\title{
Wound wood formation in Eucalyptus globulus and Eucalyptus nitens: anatomy and chemistry
}

\author{
Alieta Eyles, Noel W. Davies, and Caroline Mohammed
}

\begin{abstract}
The wound-associated wood that developed 17 months following artificial xylem injury in Eucalyptus globulus (Labill) and Eucalyptus nitens (Maiden) was examined anatomically and chemically. This new tissue located immediately adjacent to the wound site and termed "wound wood" was highly variable consisting of callus, altered wood of increased parenchyma density, and dark extractives, visible to the naked eye. Subsequent chemical analysis of crude wound wood extracts by HPLC coupled to negative ion electrospray mass spectrometry revealed the presence of a diverse range of polyphenolic compounds including hydrolysable tannins, proanthocyanidins, flavanone glycosides, and formylated phloroglucinol compounds. A number of polyphenols were unequivocally identified including engelitin, pedunculagin, and tellimagrandin I. Other compounds present in wound wood include various hydroxystilbene glycosides and volatile terpenes. The importance of the diverse range of secondary metabolites detected in wound wood is discussed in relation to tree wound repair responses.
\end{abstract}

Résumé : Les caractéristiques anatomiques et chimiques du bois associé aux blessures qui s'était développé 17 mois après avoir infligé des blessures artificielles au xylème ont été étudiées chez Eucalyptus globulus (Labill) et Eucalyptus nitens (Maiden). Ces nouveaux tissus situés immédiatement autour de la blessure et appelés « bois blessé » étaient très variés et constitués de calus, de bois altéré avec une densité plus élevée de parenchyme et plus de substances solubles de couleur noire visibles à l'œil nu. Des analyses chimiques subséquentes d'extraits bruts de bois blessé par chromatographie liquide haute performance couplée à la spectrométrie de masse avec électronébulisation d'ions chargés négativement a révélé la présence d'une gamme diversifiée de polyphénols incluant des tannins hydrolysables, des proanthocyanidines, des glycosides flavanoïdes et des phloroglucinols contenant des radicaux formyle. Plusieurs polyphénols ont été catégoriquement identifiés incluant l'engélitine, la pédunculagine, et la tellimagrandine I. D'autres composés présents dans le bois blessé incluent divers hydroxystilbènes glycosides et des terpènes volatiles. L'importance de la gamme variée de métabolites secondaires détectés dans le bois blessé est discutée en relation avec les réactions associées à la cicatrisation des blessures chez les arbres.

[Traduit par la Rédaction]

\section{Introduction}

Xylem wounding provides a major route for the entry of decay-causing fungi into living trees. Trees respond to wounding by "compartmentalizing" the wounded area to limit the spread of dysfunction and infection (Shigo and Marx 1977; Liese and Dujesiefken 1990). Compartmentalization involves both biochemical and anatomical changes of the tissues present at the time of wounding and those that

Received 8 May 2003. Accepted 9 June 2003. Published on the NRC Research Press Web site at http://cjfr.nrc.ca on 25 November 2003.

A. Eyles. ${ }^{1,2}$ Co-operative Research Centre for Sustainable Production Forestry, Private Bag 12, Hobart, Tasmania, 7001, Australia.

N.W. Davies. Central Science Laboratory, University of Tasmania, Private Bag 74, Hobart, Tasmania, 7001, Australia. C. Mohammed. Co-operative Research Centre for Sustainable Production Forestry, Private Bag 12, Hobart, and CSIRO Forestry and Forest Products, Private Bag 12, Hobart, Tasmania, 7001, Australia.

${ }^{1}$ Corresponding author (e-mail: aeyles@utas.edu.au). ${ }^{2}$ Present address: School of Agricultural Science, University of Tasmania, Private Bag 54, Hobart, Tasmania 7001, Australia. developed after wounding (Pearce 1996; Schwarze et al. 1999). Numerous investigators have studied the alterations in anatomy and histochemistry of xylem extant at the time of wounding and the new tissue formed by the vascular cambium known as the barrier zone (Bauch et al. 1980; Rademacher et al. 1984; Lowerts et al. 1986; Rioux and Ouellete 1991; Torelli et al. 1994). In contrast, the new tissue formed immediately adjacent to the wound site (referred to as callus by Shigo 1984) and directly involved in the closure of the wound has been given relatively minor consideration. We use the broader term "wound wood" instead of "callus", as the few studies that have examined the new tissue formed after wounding have found the wound wood to be highly variable consisting of both callus and altered wood (Bauch et al. 1980; Lowers et al. 1986; Torelli et al. 1994; Smith and Sutherland 1999).

Successful and rapid wound closure may be an important factor in restricting the colonization of wound-invading decay fungi. For example, in some tree species wound closure not only prevents further infections, but it is able to stop subsequent fungal development in already infected wounds, most likely by restricting gaseous exchange and moisture loss from compromised xylem, thereby creating a microenvironment inimical to fungi colonization (Boddy and Rayner 1983; Pearce 1996). Despite its importance, the new wood formed after wounding has received little attention, 
Fig. 1. ( $a$ and $b$ ) Macrograph (radial longitudinal) illustrating typical response to drill and inoculation treatment after 17 months in 9-year-old Eucalyptus globulus and Eucalyptus nitens. Outside bark in all figures is orientated towards the top of plate, while broken red line indicates boundary between extant wood and new wound wood formed after wounding. Scale bar $\sim 1 \mathrm{~cm}$. (c) Light micrograph of wound wood produced from the proliferation of healthy parenchyma at the tip of cambial dieback (blue arrow) (stain: toluidine blue). (d) Autofluorescence of wound wood stained with phloroglucinol-HCl under UV excitation (410-nm barrier filter), indicating the presence of suberin in cell walls. (e) Similar section stained with DMACA indicating the presence of proanthocyanidins (arrow). Scale bar in $c-e=200 \mu \mathrm{m}$. Note That the descending red arrow indicates new wound wood cells, while the ascending red arrow indicates extant sapwood. P, phloem; RP, ray parenchyma; VC, vascular cambium; WW, wound wood; X, xylem.

even in those northern hemisphere tree species that have been studied in more detail, e.g., Acer (Bauch et al. 1980) and Juglans (Smith 1980). The few studies that have looked at the wood formed after wounding have focused on its histological characteristics and until now, no study has yet fully investigated its chemical nature. In particular, the chemistry of wound wood has never been previously studied in any Eucalyptus species. To date, more than 200 nonvolatile secondary metabolites have been reported from various species in this relatively large genus Eucalyptus L. Heritier (Myrtaceae) (>700 species) as reviewed by Singh et al. (1999). The discovery of these compounds, however, has generally been from leaves, healthy wood and bark, and kino, a polyphenolic exudate (Hillis and Yazaki 1975; Cadahia et al. 1997; Kim et al. 2000; Close et al. 2001). The only detailed study of the chemistry of sapwood in response to wounding and infection in eucalypts is that reported by Barry et al. (2001, 2002). Inoculation with decay fungi was shown to elicit increased levels of hydrolysable tannins in the sapwood present at wounding of Eucalyptus nitens.

The objectives of this study were to characterize for the first time, the anatomical and chemical properties of the wound wood formed 17 months following artificial injury in two economically important Eucalyptus species grown in southern Australia (E. globulus and E. nitens). Chemical analyses were performed by high-pressure liquid chromatography - electrospray ionization mass spectrometry (HPLCMS), HPLC-UV, and gas chromatography - mass spectrometry (GC-MS). HPLC-MS has proved to be a valuable tool for the analysis of polyphenolics from crude and purified extracts (Nawaar et al. 1997; de Pascual-Teresa et al. 1998; Peuch et al. 1999; Barry et al. 2001; Davies and Barry 2001). The complexity of the compounds detected in wound wood and their biological significance in relation to tree wound defence is discussed.

\section{Materials and methods}

\section{Experimental site and wounding treatments}

The experimental site growing both Eucalyptus globulus (Labill) and Eucalyptus nitens (Maiden) (9 years old) was in Lewisham, approximately $50 \mathrm{~km}$ east of Hobart, Tasmania $\left(42^{\circ} 49^{\prime} \mathrm{S}, 147^{\circ} 37^{\prime} \mathrm{E}\right)$. The altitude was $20 \mathrm{~m}$ a.s.l. White et al. (1998) provides details of site establishment, fertilizer addition, and pest control of the site. In the late summer of 2000, six trees each of E. nitens and E. globulus were randomly selected for wounding treatments. At breast height (ca. $1.5 \mathrm{~m}$ ), a $10 \mathrm{~mm}$ diameter hole was drilled $3 \mathrm{~cm}$ into the outer sapwood. A second hole with identical dimensions to the first was drilled $30 \mathrm{~cm}$ above the first hole and inoculated with a decay fungus previously isolated from an
E. nitens white-rot decay column. Inoculation involved inserting $2 \mathrm{~cm} \times 1 \mathrm{~cm}$ rectangular pieces of a 2-week-old fungal culture growing on malt extract agar into the drill hole and sealing with a layer of lanolin wax. The decay fungus used for the inoculation was an unidentified basidiomycete known as "Isolate D" and is described elsewhere (Barry et al. 2002). Briefly, this isolate has been associated with large decay columns resulting from pruning wounds and was shown to be a very aggressive pathogen in both pot and field pathogenicity trials.

Approximately 17 months later, three trees each of $E$. nitens and E. globulus were harvested. Billets of ca. $50 \mathrm{~cm}$ in length that included the drill wounds were dissected with a bandsaw by cutting longitudinal sections through the wound. The responses to the drill treatments were noted. Chisel shavings (60-90 mg) of the wound wood, which only included new cells formed after wounding and had been produced adjacent to the drilling wound (Figs. 1a and $1 b$ ), as well as samples of healthy sapwood obtained from the same tree were prepared for HPLC-MS, HPLCUV, and GC-MS analysis. For HPLC-MS and HPLC-UV analyses, wound wood samples were extracted twice with $750 \mu \mathrm{L}$ of $70 \%$ aqueous acetone over $48 \mathrm{~h}$ in the dark at $4{ }^{\circ} \mathrm{C}$. The extract was then transferred to a $1.5-\mathrm{mL}$ microcentrifuge tube and centrifuged $(1300 \mathrm{r} / \mathrm{min}$ for $2 \mathrm{~min})$ to remove solids. For GC-MS analysis, wound wood samples were extracted with $2 \mathrm{~mL}$ of dicholoromethane over $24 \mathrm{~h}$ in the dark at $4{ }^{\circ} \mathrm{C}$. In both cases, samples were stored at $-20{ }^{\circ} \mathrm{C}$ and analysed within 1 week of extraction.

\section{Preparation of tissues for histological examination}

Blocks (ca. $15 \mathrm{~mm}^{3}$ ) obtained from the wound-associated wood located within the square shown in Fig. $1 a$ were fixed in formaldehyde - acetic acid - 50\% ethanol (FAA, 5:5:90 by vol.) for a minimum of $24 \mathrm{~h}$ at $4{ }^{\circ} \mathrm{C}$, dehydrated with an ethanol series, and infiltrated in a LR White acrylic resin (Proscitech, Brisbane) series. Samples were then polymerized in fresh $100 \%$ LR White resin for $8-10 \mathrm{~h}$ at $60{ }^{\circ} \mathrm{C}$ (Eyles and Mohammed 2002). Transverse and longitudinal sections of $10 \mu \mathrm{m}$ in thickness were cut with a sledge microtome, dried onto glass slides, stained with a $1 \%$ aqueous solution of toluidine blue, and permanently mounted in Cytoseal (ProSciTech, Brisbane). Tissue structure and cell changes were noted on a Zeiss Axioskop photomicroscope. Suberin was detected with the autofluroescence quenching technique (Biggs 1984). Autofluorescence of lignin was quenched with $1 \%$ phloroglucinol- $\mathrm{HCl}$, and the residual distinct blue autofluorescence was observed under a Lietz fluorescence microscope equipped with a HBO 50-W mercury lamp with BP 340-380 excitation and LP 425 barrier filters. Monomeric flavan-3-ols as well as the corresponding oligo- 


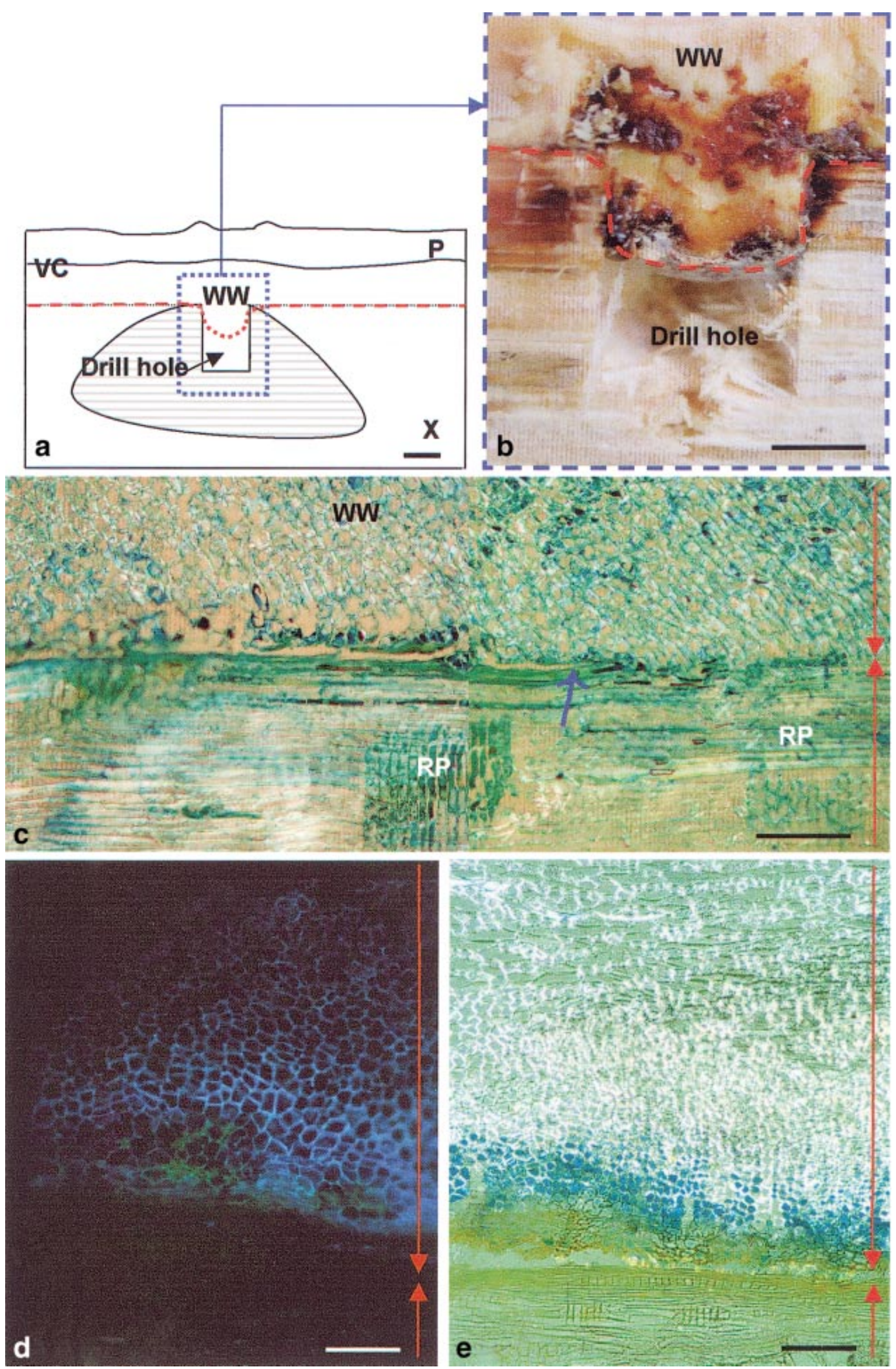


meric proanthocyanidins were detected by $p$-dimethylaminocinnamaldehyde (DMACA) with a method modified from Gutmann (1993) described elsewhere (Eyles and Mohammed 2002).

\section{Chromatographic and spectrometric analysis}

\section{HPLC-UV and HPLC-MS}

Injections of $5 \mu \mathrm{L}$ were analysed on a Waters Alliance 2690 with a Waters 996 photodiode array detector (Waters Corporation, Milford, Mass.). The column was a Waters Nova-Pak C18 column $(150 \mathrm{~mm} \times 3.9 \mathrm{~mm})$ fitted with an Alltech Econosphere $5 \mu \mathrm{m} \mathrm{C}-18$ guard cartridge (Alltech Associates Australia Pty Ltd., Melbourne, Australia). For HPLC-MS, the HPLC column outlet was coupled directly to a Finnigan LCQ ion trap mass spectrometer fitted with an electrospray source (Finnigan MAT, ThermoQuest, Co., San Jose, Calif.). Detailed description of the operating conditions for both systems can be found elsewhere in Eyles et al. (2003).

\section{$G C-M S$}

Analysis of the dicholoromethane extracts was performed by combined GC-MS using HP-5890 GC directly coupled to a Hewlett Packard 5970 B mass selective detector. The fused silica GC column was a $25 \mathrm{~mm} \times 0.3 \mathrm{~mm}$ diameter HP1 $(0.17 \mu \mathrm{m}$ film $)$, and the oven temperature was held at $20^{\circ} \mathrm{C}$ for $2 \mathrm{~min}$ and then programmed to $240{ }^{\circ} \mathrm{C}$ at $6{ }^{\circ} \mathrm{C} / \mathrm{min}$, using helium as the carrier gas. Identification of the individual compounds was based on an "in-house" library of reference mass spectra built up from standard compounds and oils of known composition and published Kovat's retention indices (Davies 1990). Splitless injections of $1 \mu \mathrm{L}$ were made at an injection temperature of $220^{\circ} \mathrm{C}$.

\section{Depolymerization of the crude wound wood extracts in the presence of phloroglucinol}

To determine the identity of the unknown high molecular mass compounds detected in the HPLC-UV chromatogram of crude wound wood extracts as a broad unresolved region (Fig. 2), the crude extracts were subjected to acid hydrolysis following a modified method outlined in Pascual-Teresa et al. (1998). For two samples each from E. globulus and E. nitens, $100 \mu \mathrm{L}$ of original wound tissue crude extract was placed in a glass Reactivial (Alltech Associates Australia Pty Ltd.) together with $300 \mu \mathrm{L}$ of phloroglucinol reagent $(80 \mathrm{mg}$ phloroglucinol dissolved in $0.5 \mathrm{~mL}$ methanol and $1.5 \mathrm{~mL}$ $0.5 \mathrm{~mol} / \mathrm{L} \mathrm{HCl}$ ). The mixture was allowed to react for $5 \mathrm{~min}$ in a water bath at $100{ }^{\circ} \mathrm{C}$. It was then cooled in water and later placed in a freezer to precipitate excess phloroglucinol. The depolymerized samples were analysed by HPLC-MS using the method described above.

The identification of compound classes and specific compounds within them was achieved by a combination of interpretation of MS and tandem MS data from first principles (Stobiecki 2000; De Freitas et al. 1998; Hammerstone et al. 1998), UV spectra, and comparison of HPLC, UV, and MS data with standards where possible. The various hydrolysable tannins were identified by comparing their negative ion ESI-MS characteristics with those previously described by Barry et al. (2001) and Davies and Barry (2001), who included the use of several authentic standards.

\section{Semi-quantification}

Calculations of the relative abundance of compound classes were based on the peak area of the HPLC-UV chromatogram, with some assignment in regions of co-elution, referred back to individual MS responses. An arbitrary classification system based on the approximate percentage of the total absorbance at $280 \mathrm{~nm}$ was then used to allow comparisons between wound wood and healthy sapwood (Table 1).

\section{Authentic standards}

Purified standards of engelitin and resveratrol glycoside were used in the study. Standards were weighed and dissolved in $70 \%$ acetone at concentrations of $0.10 \mathrm{mg} / 100 \mu \mathrm{L}$.

\section{Results}

\section{Morphological observations}

In the 17 months following injury, all drill hole wounds had fully closed over, and reestablishment of the vascular cambium was achieved (Fig. 1a). Moreover, all drill holes inoculated with the unknown decay fungus were shown to form decay columns ( $>10 \mathrm{~cm}$ in length) in E. globulus and $E$. nitens. The new tissue formed directly adjacent to the drill site termed "wound wood" was usually characterized by the presence of dark extractives (nonstructural components of wood), regardless of whether the inoculated fungus had caused decay or not (Fig. 1b). In all cases, no decay symptoms were evident in the wound wood. Moreover, fungal hyphae were not observed in the wound wood under light microscopy.

From histological studies, the wound wood was found to be highly variable comprising of callus production proximal to wounds, while distal to the wound, the formation of "wood" was characterized by altered cell orientation, reduced vessel numbers, and increased parenchyma density. The wound wood was observed to originate from the calluslike proliferation of healthy ray and axial parenchyma cells adjacent to the wounding site (Fig. 1c). The cell walls of the wound wood located directly adjacent to the dead extant xylem exhibited a distinct blue-white fluorescence, indicating the presence of suberin (Fig. 1d). Furthermore, in contrast with extant sapwood, the innermost 10-15 layers of woundassociated wood located along the extant xylem stained strongly positive with the DMACA treatment, suggesting the presence of proanthocyanidins (Fig. 1e). In light of these results, the wound wood was analysed by HPLC with ESI-MS in an attempt to elucidate the chemistry of the wood extractives.

\section{Chemical analysis}

Analysis of E. nitens and E. globulus crude wound wood extracts by GC-MS, HPLC-UV, and HPLC-MS using negative ion electrospray ionization indicated the presence of a very complex range of organic compounds, which were either undetectable in healthy tissue or present at only trace levels. These included flavonoids and flavonoid glycosides, condensed tannins, hydrolysable tannins, formylated phloroglucinol compounds (FPCs) (Eyles et al. 2003), terpenes, and hydroxystilbene glycosides (Fig. 2; Table 1). Qualitative comparisons of crude extracts between treatments showed that the same diverse range of secondary metabolites was de- 
Fig. 2. Examples of typical HPLC-UV chromatograms of wound wood extract (70\% acetone) of Eucalyptus globulus (a) and Eucalyptus nitens (b) measured at $280 \mathrm{~nm}$ indicating major and minor compounds. The unresolved peaks between 5 and 20 min largely contain proanthocyanidin (PAs) and hydrolysable tannins. The peaks between 25 and 45 min (within bracket) largely contain formylated phloroglucinol compounds (FPCs). Identities of peaks are as follows: A, unknown flavonoid; B, dihydroquercetin rhamnoside; C, dihydroquercetin arabinoside; D, engelitin; E, unknown flavonoid; F, unknown compound; G, peduculagin; H, catechin; I, tetra-galloylglucose; J, unknown stilbene glycoside; K, unknown stilbene glycoside; L, unknown compound; M, sideroxylonal.
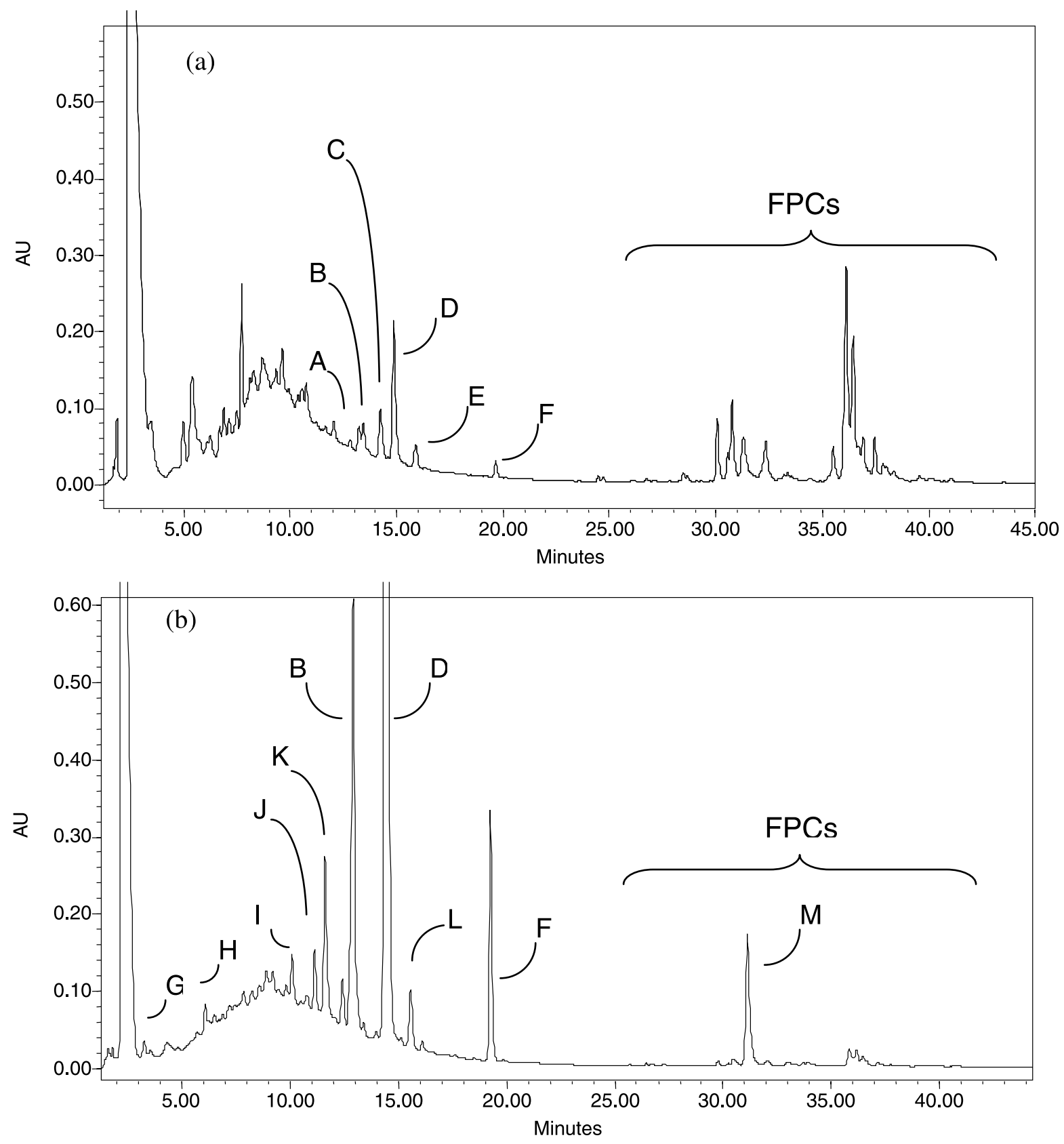

tected in wound wood obtained from trees that had been inoculated with decay fungus as those without inoculation.

\section{Compound identification}

\section{Proanthocyanidins in wound wood}

The wound wood crude extracts of both species appeared to be predominantly composed of unidentified compounds of high molecular masses observed as a broad unresolved region in the HPLC-UV chromatogram (Fig. 2). The bulk of these unknown compounds were preliminarily identified as belonging to the major group of natural polyphenolic compounds known as proanthocyanidins (PAs; syn.: condensed tannins). From interpretations of MS behaviour, the identities of a number of compounds were confirmed including catechin, procyanidin dimers, trimers, and their respective gallates (Table 1). Preliminary analysis of other unknown PAs, by acid-catalyzed cleavage with phloroglucinol as the nucleophile, resulted in a complex range of products that did not correspond to simple catechin and (or) epicatechin $(\mathrm{C}-$ E) monomers or dimers bound to phloroglucinol. Direct interpretation of MS and tandem MS data indicated that the 
Table 1. Relative abundance of the representative compounds present in crude wound wood extracts of Eucalyptus globulus and Eucalyptus nitens as determined by HPLC-UV and supported by HPLC-MS data.

\begin{tabular}{|c|c|c|c|c|c|}
\hline \multirow[b]{3}{*}{ Compound class } & \multirow[b]{3}{*}[\mathrm{M}-\mathrm{H}]{$^{-}$} & \multicolumn{4}{|c|}{ Relative abundance $^{a}$ of species } \\
\hline & & \multicolumn{2}{|c|}{ E. globulus } & \multicolumn{2}{|c|}{ E. nitens } \\
\hline & & HS & WW & HS & WW \\
\hline \multicolumn{6}{|l|}{ Flavonol } \\
\hline Dihydrokaempferol $^{b}$ & 287 & 0 & 0 & 0 & + \\
\hline Quercetin $^{b}$ & 301 & 0 & $\operatorname{tr}$ & 0 & + \\
\hline \multicolumn{6}{|l|}{ Flavanone glycosides } \\
\hline Engelitin $b$ & 433 & 0 & + & 0 & +++ \\
\hline Dihydroquercetin arabinoside & 433 & $\operatorname{tr}$ & $\operatorname{tr}$ & $\operatorname{tr}$ & $\operatorname{tr}$ \\
\hline Dihydrokaempferol arabinoside & 419 & 0 & 0 & 0 & + \\
\hline Dihydroquercetin rhamnoside & 449 & 0 & 0 & 0 & + \\
\hline \multicolumn{6}{|l|}{ Proanthocyanidins } \\
\hline Catechin $^{b}$ & 289 & 0 & + & 0 & + \\
\hline Catechin gallate & $441-$ & & & & \\
\hline Procyanidin dimers & 577 & & & & \\
\hline Unknown proanthocyanidin & 723 & & & & \\
\hline Procyanidin dimer gallates & 729 & 0 & + & 0 & + \\
\hline Procyanidin trimer gallates & 1017 & & & & \\
\hline Unknown proanthocyanidin & 1125 & & & & \\
\hline Unknown proanthocynidin & 1157 & & & & \\
\hline Polymeric proanthocyanidins & $>1200$ & 0 & +++++ & 0 & +++++ \\
\hline \multicolumn{6}{|l|}{ Hydrolysable tannins } \\
\hline Methyl ellagic acid arabinoside & 447 & 0 & + & 0 & + \\
\hline Trigalloyl glucoses & 635 & 0 & + & $\operatorname{tr}$ & + \\
\hline Pedunculagin & 783 & $\operatorname{tr}$ & + & $\operatorname{tr}$ & ++ \\
\hline Tellimagrandin $\mathrm{I}^{b}$ & 785 & 0 & $\operatorname{tr}$ & 0 & + \\
\hline Tetragalloylglucoses ${ }^{b}$ & 787 & 0 & $\operatorname{tr}$ & $\operatorname{tr}$ & ++ \\
\hline Unknown ellagitannin & 933 & 0 & + & 0 & + \\
\hline Pentagalloylglucose $e^{b}$ & 939 & 0 & + & $\operatorname{tr}$ & + \\
\hline Formylated phloroglucinol compound $(\mathrm{FPCs})^{c}$ & & 0 & +++ & 0 & 0 \\
\hline \multicolumn{6}{|l|}{ Stilbene glycosides } \\
\hline Resveratrol glycoside & 389 & 0 & 0 & 0 & + \\
\hline Astringenin & 405 & 0 & $\operatorname{tr}$ & 0 & $\operatorname{tr}$ \\
\hline a-Trihydroxy-methoxystilbene glycoside & 419 & 0 & 0 & 0 & + \\
\hline \multicolumn{6}{|l|}{ Terpenes $^{d}$} \\
\hline 1,8-Cineole ${ }^{b}$ & & 0 & \#\#\# & 0 & \#\#\# \\
\hline$\alpha$-Pinene ${ }^{b}$ & & 0 & \#\# & 0 & \#\# \\
\hline Globulol $^{b}$ & & 0 & \#\# & 0 & \# \\
\hline Aromadendrene $^{b}$ & & 0 & \#\# & 0 & $\#$ \\
\hline $\begin{array}{l}{ }^{a} \text { Relative scale where } 0 \text {, none detected; tr (trace ar } \\
50 ;+++++,>50 \text {. } \\
{ }^{b} \text { Identity confirmed with standard. HS, healthy sap } \\
{ }^{c} \text { See Eyles et al. (2003). } \\
{ }^{d} \text { Relative abundance of terpenes as determined by } \\
\text { other compound classes but noted by \#). }\end{array}$ & $\begin{array}{l}\text { ), }>0-1 ;+ \\
\text { WW, wo } \\
\text { IS (based }\end{array}$ & & & &,$++ 26-$ \\
\hline
\end{tabular}

products observed could be readily explained, however, by almost complete substitution along the oligomer or polymer backbone with rhamnose and gallic acid.

\section{Flavanone glycosides in wound wood}

The principle flavonoid glycoside detected in wound wood crude extracts (particularly in E. nitens samples) was identified as engelitin (dihydrokaempferol 3-rhamnoside, scheme 1) (Fig. 2; Table 1). Its identity was established initially on the basis of molecular mass, then tandem mass spectral data, which indicated a flavonoid aglycone of appar-
Scheme 1. Engelitin.<smiles>[R10][OH+][C@H]1C(=O)c2c(O)cc(O)cc2O[C@H]1c1ccc(O)cc1</smiles> 
ent molecular mass 288 bound to rhamnose, and finally, unequivocally by direct comparison with an authentic standard. Other related flavonoid glycosides present in significantly lower amounts included dihydrokaempferol arabinoside, dihydroquercetin glucoside, and dihydroquercetin rhamnoside. These were identified on the basis of UV, MS, and tandem MS evidence only and not by comparison with authentic standards. For example, in the negative electrospray tandem MS data, rhamnose substitution was indicated by losses 146 and (or) 164 daltons, while arabinose substitution was indicated by losses of 132 and (or) 150 daltons.

\section{Comparison of the relative abundance of compounds between species and tissue type}

Representative HPLC chromatograms of the crude wound wood extracts of E. globulus and E. nitens showed the crude extracts to be largely composed of PAs in addition to at least five other compound classes (Fig. 2). Of these other compound classes, E. globulus crude wound wood extracts contained higher levels of terpenes and FPCs than those from E. nitens wound wood. Conversely, crude extracts from E. nitens wound wood contained higher levels of the flavanone glycosides (particularly engelitin) and hydrolysable tannins than found in the crude wound wood extracts of E. globulus. In contrast, with the exception of a dihydroquercetin arabinoside and hydrolysable tannins detected in only trace amounts, the other compound classes were not detected in healthy sapwood (Table 1).

\section{Discussion}

Histological examinations showed the wound wood of both E. globulus and E. nitens to be highly variable displaying similar morphology to that reported for other tree species, i.e., comprising of both callus and altered wood (Bauch et al. 1980; Lowerts et al. 1986; Torelli et al. 1994). In addition, the wound wood was also characterized by the presence of visually obvious dark extractives. From gross morphological comparisons of the wound wood observed in the two eucalypt species with that reported for other woody angiosperms, the production of such obvious extractives appears to be a unique feature of eucalypts. For example, no such production of extractives was reported to be present in the new tissue formed after drill wounding in black walnut (Juglans nigra L.) (Smith 1980) nor in other woody tree species (Bauch et al. 1980; Lowerts et al. 1986; Torelli et al. 1994; Smith and Sutherland 1999).

Subsequent chemical analysis of the crude extracts obtained from the wound wood revealed the presence of a complex array of secondary metabolites. More specifically, at least six classes of secondary compounds were detected in the crude wound wood extracts of both E. globulus and E. nitens compared with the trace levels of two compound classes detected in healthy sapwood. Interestingly, most of the PAs detected in wound wood were not of the usual catechin or epicatechin (C-E) monomers or oligomers but were more complex PAs, substituted with rhamnose and gallic acid. The presence of 3-O- $\alpha$-L-rhamnopyranosyl-(+)catechin monomer units in condensed tannins has been previously reported in mangrove bark (Achmadi et al. 1994). These were also detected as their $(4 \alpha \rightarrow 2)$ phloroglucinol adducts from a depolymerization reaction. Furthermore, rhamnosides and gallates are well known in simple flavanol monomers and dimers (Harborne and Baxter 1999).

The findings from the present study raise questions about the biological significance of these secondary compounds in tree wound repair. From macroscopic observations, the wound wood appeared to be effective in restricting the outward spread of fungal decay into subsequent functional sapwood, even 17 months after inoculation. The accumulation of secondary compounds such as those found in the wound wood of eucalypts is generally implicated as having an antimicrobial role against pests and diseases (Woodward 1992; Pearce 1996). No wound is ever sterile of microorganisms, however, given that the qualitative composition of the secondary metabolites produced in the wound wood appeared largely independent of whether or not decay symptoms were present, we propose that these chemical extractives may have a multifunctional role (not just an antimicrobial role) in eucalypt tree defence responses. Schultz and Nicholas (2000) recently found evidence to suggest that the phenolic extractives in heartwood possessed both fungicidal and antioxidant properties. Similarly, we suggest that the diverse range of secondary metabolites may all act in a synergistic manner to aid in wound healing and discourage pathogenic growth in the compromised tissue. For instance, deleterious free radicals are generated from wounding (Doorslaer et al. 1999) and (or) by white and brown rot fungi, which are thought to have a primary role in the depolymerization of wood cell material (Hirano et al. 1997). The secondary metabolites produced in wound wood may have an antioxidant role, acting to mop up these deleterious free radicals, particularly as both high molecular mass PAs and hydrolysable tannins have already been shown to act as strong antioxidants in vitro by Hagerman et al. (1998) and more recently by our group (Eyles 2003).

In E. globulus and E. nitens, wound wood formation appeared to consistently play an important role in the wound repair process, e.g., physically sealing off the wound site and reestablishing continuity of the vascular cambium as well as restricting the outward spread of infection into subsequent healthy tissue. Admittedly, this latter conclusion can only be drawn for the one decay species used in this study. Furthermore, an array of secondary metabolite classes were detected in the crude wound wood extracts. While the precise role of extractives in eucalypt tree defence remains unclear, the present study provides much needed background information on the chemistry of wound responses. As mentioned earlier, the chemistry of wound wood has never been analysed in other woody tree species. In future studies, it wound be interesting to compare the wound wood chemistry of these other tree species with those of eucalypts. Such studies may reveal that the importance of wound wood in tree compartmentalization of injury and infection may have been overlooked, particularly for those species with rapid wound occlusion rates.

\section{Acknowledgements}

We thank Dr. Ted Hillis for standards of dihydrokaempferol, engelitin, and resveratrol, and to Dr. Karen Barry and Dr. Yoshi Yazaki for standards of the various 
hydrolysable tannins. We thank Dr. Ted Hillis and Dr. Karen Barry for reviewing drafts of the manuscript. A.E. was supported by a University of Tasmania Strategic Scholarship with additional funding from the Co-operative Research Centre for Sustainable Production Forestry.

\section{References}

Achmadi, S., Syahbirin, G., Choong, E.T., and Hemingway, R.W. 1994. Catechin-3-O-rhamnoside chain extender units in polymeric procyanidins from mangrove bark. Phytochemistry, 35: 217-219.

Barry, K.M., Davies, N.W., and Mohammed, C.M. 2001. Identification of hydrolysable tannins in the reaction zone of Eucalyptus nitens wood by high performance liquid chromatographyelectrospray ionization mass spectrometry. Phytochem. Anal. 12: $120-127$.

Barry, K.M., Davies, N.W., and Mohammed, C.M. 2002. Effect of season and different fungi on phenolics in response to xylem wounding and inoculation in Eucalyptus nitens. For. Pathol. 32: 163-178.

Bauch, J., Shigo, A.L., and Starck, M. 1980. Wound effects in the xylem of Acer and Betula species. Holzforschung, 34: 153-160.

Biggs, A.R. 1984. Occurrence and location of suberin in wound reaction zones in xylem of 17 tree species. Phytopathology, 77: 718-725.

Boddy, L., and Rayner, A.D.M. 1984. Origins of decay in living deciduous trees: the role of moisture content and reappraisal of the expanded concept of tree decay. New Phytol. 94: 623-641.

Cadahia, E., Conde, E., Garcia Vallejo, M.C., and Fernandez De Simon, B. 1997. Tannin composition of Eucalyptus camaldulensis, E. globulus and E. rudis: wood. Holzforschung, 51: 119-124.

Close, D.C., Davies, N.W., and Beadle, C.L. 2001. Temporal variation of tannins (galloylglucoses), flavonols and anthocyanins in leaves of Eucalyptus nitens seedlings: implications for light attenuation and antioxidant activities. Aust. J. Plant Physiol. 128: 269-278.

Davies, N.W. 1990. Gas chromatographic retention indices of monoterpenes and sesquiterpenes on methyl silicone and Carbowax $20 \mathrm{M}$ phases. J. Chromatogr. 503: 1-24.

Davies, N.W., and Barry, K.M. 2001. Negative ion electrospray HPLC/MS ${ }^{\mathrm{n}}$ of hydrolysable tannins. In Advances in mass spectrometry. Edited by E. Gelpi. John Wiley \& Sons, New York. pp. 893-894.

De Freitas, V.A.P., Glories, Y., Bourgeois, G., and Vitry, C. 1998. Characterisation of oligomeric and polymeric procyanidins from grape seeds by liquid secondary ion mass spectrometry. Phytochemistry, 49: 1435-1441.

De Pascual-Teresa, S., Gutierrez-Fernandez, Y., Rivas-Gonzalo, J.C., and Santos-Buelga, C. 1998. Characterization of monomeric and oligomeric flavan-3-ols from unripe almond fruits. Phytochem. Anal. 9: 21-27.

Doorslaer, S., van, Dedonder, A., De Block, M., and Callens, F. 1999. Oxidative stress in plants. EPR monitoring in DMPODMSO based extracts. J. Plant Physiol. 154: 132-136.

Eyles, A. 2003. Wound responses of Eucalyptus globulus and E. nitens: anatomy and chemistry. Ph.D. dissertation, University of Tasmania, Australia.

Eyles, A., and Mohammed, C. 2002. Comparison of CEPA (2chloroethyl phosphonic acid) induced responses in juvenile $\mathrm{Eu}$ calyptus nitens, E. globulus and E. obliqua: a histochemical and anatomical study. IAWA J. 23: 419-430.
Eyles, A., Davies, N.W., and Mohammed, C. 2003. Novel detection of formylated phloroglucinol compounds (FPCs) in the wound-associated wood of Eucalyptus globulus and E. nitens. J. Chem. Ecol. 29: 881-898.

Hagerman, A.E., Riedl, K.M., Jones, G.A., Sovik, K.N., Ritchard, N.T., Hartzfeld, P.W., and Riechel, T.L. 1998. High molecular weight plant polyphenolics (tannins) as biological antioxidants. J. Agric. Food Chem. 46: 1887-1892.

Hammerstone, J.F., Lazarus, S.A., Mitchell, A.E., Rucker, R., and Schmitz, H.H. 1998. Identification of procyanidins in cocoa (Theobroma cacao) and chocolate using high-performance liquid chromatography/mass spectrometry. J. Agric. Food Chem. 47: 490-496.

Harborne, J.B., and Baxter, H. (Editors). 1999. The handbook of natural flavonoids. Vol. 2. John Wiley \& Sons, U.K. pp. 355-514.

Hillis, W.E., and Yazaki, Y. 1975. Kinos of Eucalyptus species and their acid degradation products. Phytochemistry, 13: 495-498.

Hirano, T., Tanaka, H., and Enoki, A. 1997. Relationship between production of hyroxyl radicals and degradation of wood by the brown rot fungus, Tyromyces palustris. Holzforschung, 51: 389 395.

Kim, J.P., Lee, I.K., Yun, B.S., Chung, S.H., Shim, G.S., Koshino, H., and Yoo, I.D. 2000. Ellagic acid rhamnosides from the stem bark of Eucalyptus globulus. Phytochemistry, 57: 587-591.

Liese, W., and Dujesiefken, D. 1990. Principles of compartmentalisation in trees. IIIrd Euro African Regional Wood Anatomy Symposium organized by the Wood Science and Technology Laboratories of the Swiss Federal Institute of Technology, Switzerland. IAWA Bull. 11: 129-130.

Lowerts, G., Wheeler, E.A., and Kellison, R.C. 1986. Characteristics of wound-associated wood of yellow-poplar (Liriodendron tulipifera L.). Wood Fiber Sci. 18: 537-552.

Nawaar, M.A.M., Marzouk, M.S., Nigge, W., and Linscheid, M. 1997. High performance liquid chromatographic/electrospray ionization mass spectrometric screening for polyphenolic compounds of Epilbium hirsutum - the structure of the unique ellagitannin epilobamide-A. J. Mass Spectrom. 32: 645-654.

Pearce, R.B. 1996. Tansley review No. 87. Antimicrobial defences in the wood of living trees. New Phytol. 132: 203-233.

Puech, J.L., Mertz, C., Michon, V., Guerneve, T., Doco, C.L., and Du Penhoat, C.H. 1999. Evolution of castalagin and vescalagin in ethanol solutions. Identification of new derivatives. J. Agric. Food Chem. 47: 2060-2066.

Rademacher, P., Bauch, J., and Shigo, A.L. 1984. Characteristics of xylem formed after wounding in Acer, Betula and Fagus. IAWA Bull. 5: 141-151.

Rioux, D., and Ouellette, G.B. 1991. Barrier zone formation in host and nonhost trees inoculated with Ophiostoma ulmi. I. Anatomy and histochemistry. Can. J. Bot. 69: 2055-2073.

Schultz, T.P., and Nicholas, D.D. 2000. Naturally durable heartwood: evidence for a proposed dual defensive function of the extractives. Phytochemistry, 54: 47-52.

Schwarze, F.W.M.R., Engels, J., and Mattheck, C. 1999. Fungal strategies of wood decay in trees. Springer-Verlag. Berlin. pp. $138-167$.

Shigo, A.L. 1984. Compartmentalization: a conceptual framework for understanding how trees grow and defend themselves. Annu. Rev. Phytopathol. 22: 189-214.

Shigo, A.L., and Marx, H.G. 1977. Compartmentalization of decay in trees. USDA For. Serv. Agric. Inf. Bull. 405.

Singh, A.K., Khare, M., and Kumar. S. 1999. Non-volative constituents of eucalypts: a review on chemistry and biological activities. J. Med. Aromatic Plant Sci. 21: 375-407. 
Smith, D.E. 1980. Abnormal wood formation following fall and spring injuries in black walnut. Wood Sci. 12: 243-251.

Smith, K.T., and Sutherland, E.K. 1999. Fire-scar formation and compartmentalization in oak. Can. J. For. Res. 29: 166-171.

Stobiecki, M. 2000. Application of mass spectrometry for identification and structural studies of flavonoid glycosides. Phytochemistry, 54: 237-256.

Torelli, N., Krizaj, B., and Oven, P. 1994. Barrier zone (CODIT) and wound-associated wood in beech (Fagus sylvatica L.). Holzforsch. Holzverwert. 3: 49-51.
White, D.A., Beadle, C.L., Worledge, D., Honeysett, J.L., and Cherry, M.L. 1998. The influence of drought on the relationship between leaf and conducting sapwood area in Eucalyptus globulus and Eucalyptus nitens. Trees Struc. Funct. 12: 406-414.

Woodward, S. 1992. Responses of gymnosperm bark tissues to fungal invasions. In Defense mechanisms of wood plants against fungi. Edited by R.A. Blanchette and A.R. Biggs. SpringerVerlag, Berlin. pp. 62-75. 